\title{
Peripheral Hemangioblastoma
}

National Cancer Institute

\section{Source}

National Cancer Institute. Peripheral Hemangioblastoma. NCI Thesaurus. Code C157450.

A hemangioblastoma that arises from peripheral nerves or extraneural tissues. 